\title{
Okinawa goes recruiting
}

Research freedom proves trump card for interdisciplinary Japanese institute.

\section{BY DAVID CYRANOSKI}

$\mathrm{I}$ fyou're a young American or European scientist and want freedom to pursue your own research, where do you go? Some promising young researchers have made a surprising choice: a research institute on Okinawa, one of the most southerly and remote islands in Japan. After a decade of slow growth, the institute has a new president-elect, former Stanford University physicist Jonathan Dorfan, a bumper crop of new faculty, and plans to open its doors as a graduate university later this year.

For young researchers, freedom is scarce in Japanese academia, with its strict hierarchy. And Japan's universities have not had great success in attracting foreign faculty because they offer few lifetime positions for newcomers. Despite two decades of attempted internationalization, the proportion of foreign faculty members at Japanese universities hovers at around 3\%. As for Okinawa, its weak infrastructure and moribund economy make it an unlikely spot for a world-class research institute.

The Japanese government hoped to invigorate both Japanese science and Okinawa when it conceived the Okinawa Institute of Science and Technology (OIST) in 2001 as an oasis of international, interdisciplinary research. Required to find $50 \%$ of its faculty and students from outside Japan, the institute has no departments and no hierarchy of junior and senior professors. Its president answers to an international board of governors made up of prominent scientists. Its resort-like facility, tucked into protected forests and overlooking the sea, is designed to

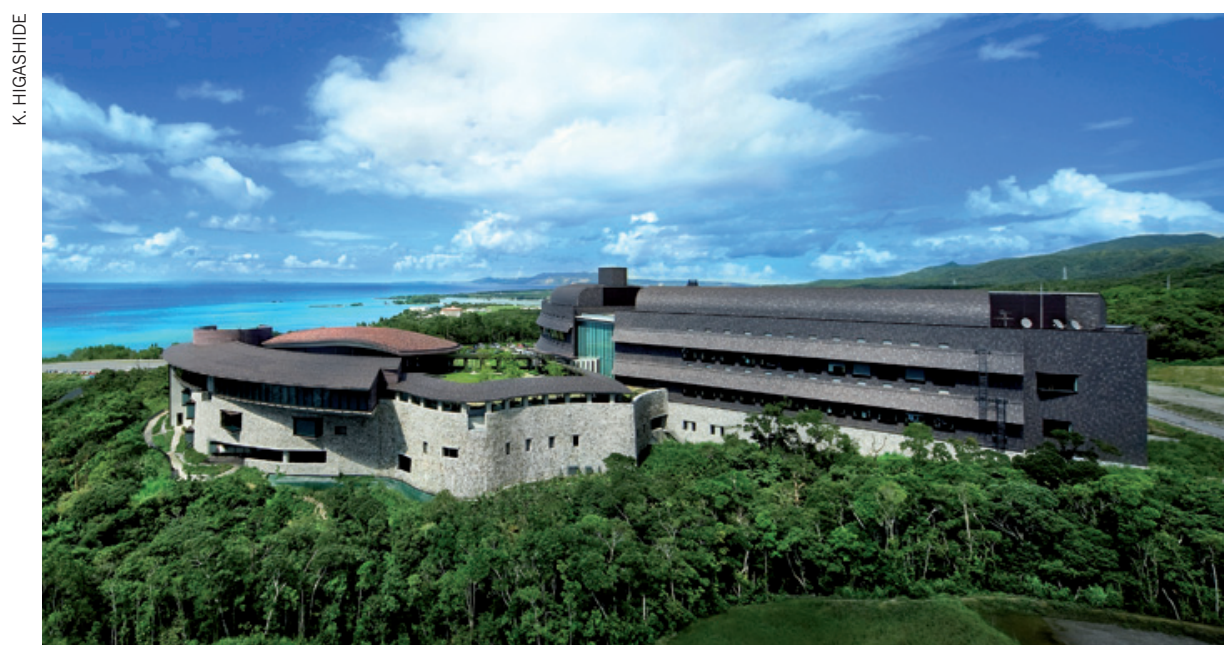

The main building and labs of the $\$ 300$-million Okinawa Institute campus will be finished next year. foster mingling. And it pays top salaries and offers faculty generous start-up funding.

Under its first president, Nobel laureate Sydney Brenner, the OIST hired its first four research groups - all Japanese - in 2004 and eventually grew to about 25 faculty members, dominated by biologists. But critics viewed roughly US $\$ 100$ million a year, as exorbitant. To gain accreditation as a graduate university and host graduate students, the institute would have to prove it could attract quality faculty.

Hired last July to lead the OIST once it becomes a university, Dorfan has plunged into that effort, taking on politics, administrative duties, public outreach and recruitment. $\mathrm{He}$ has introduced a tenure system, offering scientists - even foreigners - the opportunity of a secure lifelong career. Lavish funding and an idyllic setting, he says, will go only so far in overcoming fears about intellectual isolation and the challenge of attracting graduate students to a remote location. "Asking people to come here is not trivial. If we can't offer tenure, it would be suicide in terms of recruiting," says Dorfan.

Over three weeks in December 2010, 27 potential recruits visited the institute. "It's the biggest recruiting drive I know of," says Dorfan, and it became manageable only after Dorfan's wife suggested that candidates visit together and sit in on each other's job talks. “They weren't competing against each other. its remote location as a handicap and its cost,
They were competing against a bar," he says.

Dorfan made 26 offers. So far, according to a list he provided to Nature, 20 candidates have accepted, including 11 physicists. Dorfan expects that this success will earn the OIST university accreditation this autumn; it will then start accepting graduate students for 2012. Eventually, the OIST aims to have a total of 2,400 scientists, including graduate students and 300 faculty, in a wide range of specialities, although special strengths in marine science, neuroscience and imaging are already emerging.

With an average age of 41 , most of the recruits are young, although the OIST has already offered some greying scientists a chance to continue - and even expand their careers. In the two years since he was forced out of Kyoto University at retirement and hired by the OIST, marine biologist Nori Satoh has put together a project fitted to his new workplace: sequencing coral genomes in search of clues to why some local species suffered bleaching in 1998 after a particularly hot summer, whereas others resisted it.

Facilities are part of the allure, including a \$9.2-million table-top synchrotron for structural analysis, electron microscopes and a \$5-million coastal ocean-observing system. Tsumoru Shintake, whose group designed Japan's recently unveiled X-ray free-electron laser while at the Japanese research institute RIKEN, is one of the new recruits. He plans to build a new type of low-energy electron microscope to make three-dimensional images of DNA and other biological molecules in solution. The OIST also has two-photon microscopes and state-of-the art gene sequencers. "I believe in instruments", says Dorfan.

But the main draw is freedom. Each principal investigator post comes with five years of guaranteed research funding, along with support for graduate students and postdocs. "I have been offered all the support needed to carry out the research I want to do," says Pinaki Chakraborty, a 31-year-old fluid mechanics specialist at the University of Illinois, UrbanaChampaign. "No strings attached."

Evan Economo, a 29-year-old ecologist and postdoctoral researcher at the University of Michigan, echoes that perspective. "Once it sunk in how many resources I would have available [at the OIST], I realized I would need an incredible run with the National Science Foundation to match that in the US. I feel like my research success is now up to me instead of an anonymous grant-review panel." - SEE EDITORIAL P.54I 